\title{
Editorial
}

\section{Acta Ortopédica Mexicana en perspectiva}

\author{
González-Velasco MF*, Encalada-Díaz MI**
}

Las ciencias médicas ofrecen a los especialistas una formación integral, capacitándolos en la metodología de la investigación clínica para la integración de su trabajo de atención médica y las actividades propias de la misma. Es por eso que un médico debe aportar su granito de arena para el avance de su disciplina. En nuestro caso, cuando esto sucede el ortopedista experimenta un gran placer y si esto lo vuelve una constante, pues mucho mejor. ${ }^{1}$

Cuando se logra resolver algún problema, ocurre algún descubrimiento o aportación al conocimiento, se siente una satisfacción, ya que se ha logrado, con gran esfuerzo, obtener un resultado. Éste se manifiesta con la publicación de un trabajo para que sus pares conozcan dichas aportaciones. El solo hecho de aportar algo nuevo, por pequeño que parezca, constituye una motivación fundamental para seguir investigando y aprendiendo.

Acta Ortopédica Mexicana, órgano de difusión de nuestro colegio, reúne artículos originales, revisiones, técnicas quirúrgicas, reportes de caso, entre otros materiales, garantizando de esta manera una elevada calidad y fiabilidad, ya que dichos artículos son enviados por ortopedistas, en su mayoría, de manera voluntaria para ser sometidos a revisión por pares de la especialidad. También se presentan revisiones especiales, cartas al editor y consensos que se originan del encargo directo del comité editorial a profesionales con amplia experiencia en el ramo, lo que representa un valor añadido, pues aportan opiniones muy concretas sobre determinados aspectos biomédicos.

En esta ocasión ponemos en perspectiva el trabajo de Acta Ortopédica Mexicana en este último año para así seguir motivando a nuestros investigadores y lectores a participar con nosotros y continuar enriqueciendo la investigación y la ortopedia en México.

Durante 2018 se recibieron 97 extensos para ser sometidos al proceso de posible publicación y en el Volumen 32 se publicaron un total de 66 artículos, los cuales se desglosan en las tablas siguientes:

\begin{tabular}{|cccc|}
\hline Año & Ingresados & Nacionales & Extranjeros \\
\hline 2018 & 97 & 78 & 19 \\
\hline
\end{tabular}

Nacionales $80 \%$

Extranjeros $22 \%$

España, Colombia, Argentina, Venezuela, Ecuador y Puerto Rico

\begin{tabular}{|cccc|}
\hline Año & Publicados & Originales & Reportes de caso \\
\hline 2018 & 66 & 78 & 19 \\
\hline Revisiones & \multicolumn{2}{c}{ Editoriales } & Cartas al Editor \\
\hline 6 & 4 & 1 \\
\hline
\end{tabular}

Nacionales $72 \%$

Extranjeros 28\%

Como se observa, se concluye un año muy positivo y productivo para Acta Ortopédica Mexicana gracias a la colaboración de nuestros autores, revisores y comité editorial que hacen de esta revista una de las más consultadas de la especialidad en América Latina.

¡Gracias a todos!

Bibliografía

1. Pulido M. Publicaciones biomédicas. Med Clin (Barc). 1975; 65: 156-7.

\footnotetext{
* Coordinadora editorial.

** Editor en jefe.

Acta Ortopédica Mexicana

Dirección para correspondencia:

Revista Acta Ortopédica Mexicana

E-mail: revista@samo.edu.mx / aomrevista@gmail.com
}

Este artículo puede ser consultado en versión completa en http:// www.medigraphic.com/actaortopedica 